\title{
Viewpoint
}

\section{Assessing diagnostic errors: when is suspension of a pathologist justified?}

\author{
M Lesna
}

In 1995 , of 120 doctors who had been suspended and investigated for incompetence by the study group of the Society of Clinical Psychiatrists, five were haematologists and 14 histopathologists. Only $16 \%$ of suspensions were proven justified at a tribunal. Two haematologists and three pathologists were reinstated, three haematologists and five pathologists accepted a settlement, four pathologists were dismissed, and two cases were sub judice. Furthermore, this study showed that "women doctors are much less likely to get their jobs back than men whilst, at the same time, more often found not guilty of any professional misdoing".

In the past few years histopathologists in Great Britain have frequently been accused of diagnostic or professional incompetence, and their employers sought the names of assessors, reputable pathologists, to review a list of diagnostic mistakes. The results of the reviews have usually not been made known to the Royal College of Pathologists; the assessors, having negotiated their contracts directly with the employing NHS Trusts, produced the reports for the trust while the investigated pathologist was suspended or on the sick list. Reasons for an investigation are often hostility within the department or personality clashes, but frequently they remain obscure. Often the case is initiated by an article in a local newspaper, the pathologist being accused of a major mistake, the consequences of which may or may not be spelt out. Histopathologists are particularly vulnerable if they are involved in cancer screening programmes. Zero error is expected by the public and administrators, and the fear of litigation following a false negative diagnosis is beginning to threaten various screening programmes.

In June 1996 the College of American Pathologists hosted an international conference on liability and quality issues in cervical vaginal cytology where the standard of practice and possible solutions were discussed. ${ }^{2}$ The Board of Directors of the California Society of Pathology issued guidelines for review of cervical smears in the context of potential litigation. Among many important points, the guidelines clearly state that zero error is an unreasonable expectation that cannot be achieved even with the use of automated re-screening devices, and that even skilled screening cytologists have an irreducible false negative rate of at least $5 \%$. The California pathologists have accepted that all laboratories make mistakes and a false negative result is not necessarily evidence of substandard practice. Errors should not be judged in isolation but in the context of the overall performance of that laboratory. In their guidelines, the California Society of Pathology also warned against biased reviews performed with hindsight knowledge, and regarded as unethical reviewing by experts who did not practise routine diagnostic cytopathology. The society advised that the degree of difficulty should be established in a fashion simulating normal practice of "reasonable" cytologists without knowledge of the clinical outcome or litigation.

It seems logical to extend this method of reviewing errors to histopathological diagnosis where the variation of opinion and subjectivity of assessment by pathologists may frequently lead to variation in diagnoses that may be seen as errors. The results of studies concerned with error rates in histopathology vary widely (no serious errors, ${ }^{3} 0.26 \%,{ }^{4}$ up to $1.2 \%$ of histopathological reports ${ }^{5}$ ) but these were performed in academic or teaching institutions.

During the past decade various presentations to the Pathological Society of Great Britain and Ireland demonstrated true interobserver variation, and this should be considered in calculating the likelihood of diagnostic errors in histopathology. In establishing what is an acceptable or realistic error-what variation of opinion is unavoidable - we could use the experience of the Scottish Panel for the Consistency of Histopathological Reporting who, over the years, examined observer variability in the reporting of biopsies results of the cervix, bladder, rectum, bronchus and, recently, prostate. ${ }^{6}$ The panel established that pathologists are reliable in recognising the entity but inconsistent in quantifying the degree (grade of tumours, depth of invasion). Similarly, a review of 100 randomly selected bronchial biopsies by 11 histopathologists ${ }^{7}$ demonstrated generally good ability to distinguish between small cell and non-small cell carcinoma, but great variation in subclassifying the non-small cell tumours. Dermott and colleagues $^{8}$ found considerable disagreement between six observers assessing radial and vertical growth of malignant melanoma in a large
Accepted for publication 24 November 1997 
proportion of 94 investigated cases, immediately after the pathologists had read the article describing the benefits and pitfalls of that method. The Leicester local external quality assessment system (EQAS) results of measuring Breslow depths of malignant melanoma showed up to $84 \%$ agreement between pairs of observers, but agreement with the original report was as low as $74 \%$. Colloby and colleagues ${ }^{9}$ showed similar interobserver variation in measuring Breslow depth of thin cutaneous malignant melanoma.

Two experienced pathologists independently reviewing six classifications of ductal carcinoma in situ disagreed between grade I and II in $62.2 \%$, between grade II and III in $39.9 \%$, in the assessment of the architecture in $34.4 \%$, and necrosis in $17.7 \%$ of cases. ${ }^{10}$ Another study assessing the interobserver and intraobserver variability in identifying the area of greatest mitotic activity in breast carcinoma showed wide variations in both area selection and the mitotic counts. ${ }^{11}$ It has been shown previously that there is poor agreement between establishing the grade and subtype of invasive breast carcinoma and presence of atypical hyperplasia. ${ }^{12}$ Major differences of opinion and great interobserver variation occur in instances where grading has to be used, cervical intraepithelial neoplasia (CIN) being the most common field of disagreement. This has been a subject of several studies over the past 15 years, and a recent article by McCluggage et al suggests that there has been no improvement. ${ }^{13}$ It is not just poor agreement in the differentiation of low grades of CIN from koilocytosis but also distinction of CIN II and III from normal squamous epithelium and immature squamous metaplasia. The interobserver agreement among six independent histopathologists of 125 consecutive colposcopic cervical biopsy samples using CIN and Bethesda grading systems was poor, with $\kappa$ values ranging from 0.05 to 0.34 and 0.2 to 0.54 between individual pairs. In addition, the contribution of gynaecologists in supplying poor, unrepresentative, or misleading samples may not be negligible. ${ }^{14}$ When Banff criteria for histological diagnosis of rejection were used in renal allograph biopsies, acute rejection was overestimated, and in 14 of the 38 biopsy samples labelled borderline, the clinical diagnosis was that of acute rejection. The subjective nature of diagnosing abnormality of duodenal mucosa was demonstrated in a blind, retrospective review of paediatric samples of duodenal/jejunal mucosa: the diagnosis was changed in nine of 80 cases. ${ }^{15}$

The system of retrospective assessment of another pathologist's work by two willing assessors working for a fee, producing a report with recommendations for the employer but not for the College, may be seen as punitive and unfair. It does not reflect the initial diagnostic situation, the assessors may not have worked independently, and they know there has been a complaint. Even if the alleged incompetence is not confirmed, clearing one's name is not easy, and "not guilty" is not the same as innocent. A detailed account of one case with subsequent reaction, was published in $A C P$ News, ${ }^{16}$ and there are other cases with similar destruction of professional reputation and private life.

Having become members of the College by examination, we have proved that we have reached the required standard of diagnostic competence. Taking part in external quality assessment and continuing medical education activities helps us keep up to date with new developments in our specialties. Many members feel that it should be the College that decides whether they are still competent and that the College should determine when an error is significant. The Royal College of Pathologists is balancing its function between upholding high standards, while accepting that errors are unavoidable, and looking after its members, none of whom is infallible. At present, the defence of an erring pathologist is difficult for the Medical Defence Union and Medical Protection Society as the acceptable error rate of a "reasonable" pathologist has not been defined. It is often not clear what significant error is, or when a pathologist is guilty. Most diagnostic pathologists practise general pathology, with or without a special interest, and their errors should not be judged by an expert but by their peers. The College Advisory Group on Professional Competence and the panel of peers have now been established. It would be helpful to them if practising committed district pathologists expressed their views on the frequency, significance, and causes of various diagnostic errors as they occur in real life, and define their own achievable standards and limitations. A recent questionnaire survey by Furness and Lauder of 1021 practising pathologists produced a lukewarm response of less than $20 \%$. However, only 47 pathologists who responded had not been aware of any errors in the previous five years. ${ }^{17}$ It has been suggested in the USA that false negative rates of 5-10\% may be an admirable goal in cytopathology, and rates below $15-20 \%$ are a possible standard. ${ }^{18}$

We have witnessed the destructive effect of media publicity concerning various reviews of cervical screening and mammography on recruitment to the specialties, and we can hardly fathom the costs of these reviews to the NHS. Are we not able to explain to the public that all diagnostic and screening procedures aim for the correct diagnosis but carry a certain rate of error, which does not mean incompetence, and that zero error cannot be expected?

Suspension of an experienced consultant pathologist, a review of that pathologist's work, and the employment of a locum pathologist is probably more expensive than financial compensation for the damage caused to a patient by the pathologist's diagnostic error, if such a mistake truly occurred. The role of clinicians in the investigation of a patient should not be overlooked. They supply the pathologist with clinical information - which we expect to be correct and relevant-and, with their knowledge of the patient, they should be able to detect or suspect that the proffered pathological diagnosis may be wrong. When does the 
diagnostic dilemma become a diagnostic error? Is a locum pathologist immune from making mistakes, available to deputise for the suspended colleague, and willing to take the risk? Are there any infallible doctors around?

1 Tomlin PJ. It could be you [commentary]. Fournal of Continuing Medical Education 1997;41:5-9.

2 Stanley MW. Quality and liability issues with the Papanicolau smear: the role of professional organisations in reform initiatives. Arch Pathol Lab Med 1997;121:327-30.

3 Cree IA, Guthrie W, Anderson JM, et al. Departmental audit in histopathology. Pathol Res Pract 1993;189:453-7.

4 Safrin RE, Back CJ. Surgical pathology signout-routine Safrin RE, Back CJ. Surgical pathology signout-routine
review of every case by a 2 nd pathologist. Am $\mathcal{F}$ Surg Pathol review of every case

5 Lind AC, Bewtra C, Healy JC, et al. Prospective peer review in surgical pathology. Am f Surg Pathol 1995; 104:560-6.

6 Lessels AM, Burnett RA, Howatson SR, et al. Observer variability in the histopathological reporting of prostatic needle biopsy specimens [abstract]. 172nd meeting of the Pathological Society of Great Britain and Ireland, 3-5 January 1996, London.

7 Burnett RA, Swanson Beck J, Howatson SR, et al. Observer variability in the histopathological reporting of malignant bronchial biopsies [abstract]. 169th meeting of the Pathological Society of Great Britain , 6-8 July 1994, Glasgow.

Dermott NC, Hayes D, Al-Sader M, et al. How consistent are pathologists in determining whether malignant melanoma is radial or vertical growth phase [abstract]. 173 rd meeting of the Pathological Society of Great Britain and Ireland, 10-12 July 1996, Southampton.

9 Colloby PS, Fletcher A, West KP. Interobserver variation in the measurement of Breslow depth in thin primary cutane- ous malignant melanomas [abstract]. 160th meeting of the Pathological Society of Great Britain and Ireland, 3-5 January 1990, London.

10 Gupta SK, Douglas-Jones AG, Attanoos RL, et al. Comparison of six classifications of ductal carcinoma in situ (DCIS) of the breast [abstract]. 173rd meeting of the Pathological Society of Great Britain and Ireland, 10-12 July 1996, Southampton.

11 Johnson JS, Cross SS, Dube AK, et al. An assessment of the inter- and intra-observer variability in identifying the area of greatest mitotic activity in breast carcinomas. 175th meeting of the Pathological Society of Great Britain and Ireland, 2-4 July 1997, Sheffield.

12 Sloane JP, Ellman R, Anderson TJ, et al. Consistency of histopathological reporting of breast lesions detected by screening: findings of the UK National External Quality Assessment (EQA) Scheme. UK National Co-ordinating Group for Breast Screening Pathology. Eur 7 Cancer 1994; 30A(10):1414-19.

13 McCluggage WG, Bharucha $\mathrm{H}$, Caughley LM, et al. Interobserver variation in the reporting of cervical colposcopic biopsy specimens: comparison of grading systems. F Clin Pathol 1996;49:833-5.

14 Buxton BJ, Luesley DM, Shafi MI, et al. Colposcopically directed punch biopsy: a potentially misleading investigation. Br f Obstet Gynaecol 1991;98:1273-6.

15 Hartman G, McCormick F, Sundaresan M, et al. The subective nature of diagnosing coeliac disease [abstract]. 170th meeting of the Pathological Society of Great Britain and Ireland, 4-6 January 1995, Oxford.

16 Conroy B. A cause for some concern [letter]. ACP News, Winter 1996:52-4.

17 Furness PN, Lauder I. A questionnaire-based survey of errors in diagnostic histopathology throughout the United Kingdom. F Clin Pathol 1997;50:457-60.

18 De May RM. To err is human - to sue [editorial]. Diagn Cytopathol 1996;15:iii-vi. 